\title{
The development of DSR roll disintegrated comprehensive test bed
}

\author{
Huan He \& Heng Cao \\ School of Mechanical and Power Engineering, East China University of Science and Technology, Shanghai, \\ China
}

\begin{abstract}
Baosteel cold rolled sheet production equipment technology has very important position in Baosteel steel production, and the DSR roll is the key components in the cold rolled sheet production equipment. This paper conducted the research on key technology of DSR roll, in view of the DSR roll exposed several problems in the use, develop the DSR roll disintegrated comprehensive test device, put forward the corresponding test and solutions, ensuring safe and reliable operation of the production process.
\end{abstract}

KEYWORD: DSR roll; Disintegrated; Test

\section{GENERAL INTRODUCTION}

The DSR dynamic plate shape control technology is a kind of high-tech technology in the field of shape control, in the field of non-ferrous metallurgy rolling, especially in aluminum rolling it has been especially widely used in industry. The baosteel 2030 rolling mill apply the DSR technique into the field of steel rolling for the first time in the world, improve the quality of the steel production, it is the necessary equipment currently to produce high surface quality of automobile outer panel of. But after using for many years the hydraulic system of dynamic plate type support roller has unstable operation, the maintenance process is more complex, and economic losses caused by the big faults is also evident. Because all the control elements and detecting elements are based in the roll, any element has small damage, we should replace the roller from the rack, and then conduct the disintegration and replacement. So ensuring the performance of each element in the process of disintegration is particularly important, urgently need a set of comprehensive test equipment to finish the work.

\section{THE WORKING PRINCIPLE OF DSR ROLL}

\subsection{Introduction of DSR roll working principle}

The DSR (Dynamic Shape Roll), namely Dynamic plate type of backup Roll. The DSR technology complete the strip flatness control of rolling mill through directly controlling the distribution of contact pressure between rolls. Baosteel 2030 five-stand cold tandem mill machine working principle dia- gram and the fifth frame DSR roll working schematic diagram are shown in figure 1 and figure 2.

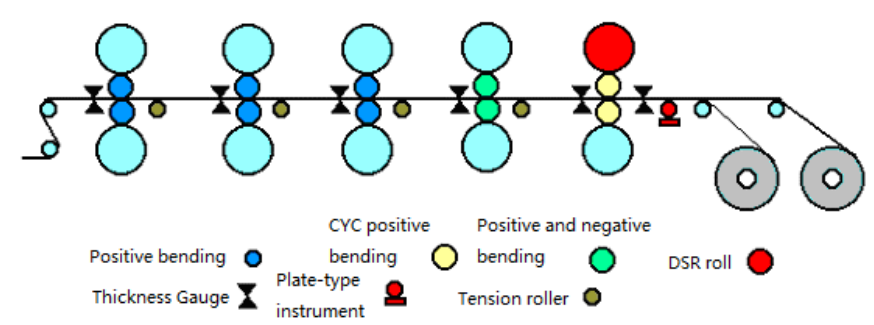

Fig.1. Baosteel 2030 five-stand cold tandem mill machine working principle diagram

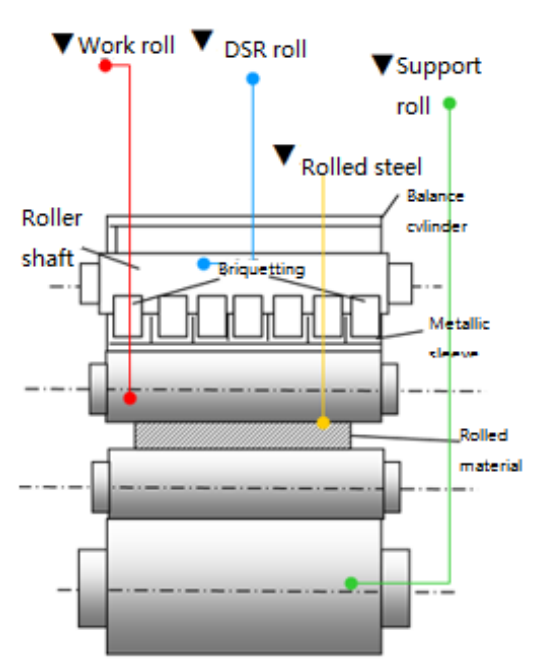

Fig.2. The fifth frame DSR roll working schematic diagram 


\subsection{The structure and working process of the DSR roll}

The core of DSR technology is a support roller with complex structure, mainly contain a still spindle in the work, a roller sleeve with roller spinning and seven hydraulic pressure piece that can adjust independently their relative position between roller shell inner surface and the spindle (from left to right with M1, M2, M3, M00, 01, 02, 03 representation), the DSR roll structure diagram is shown in figure 3.

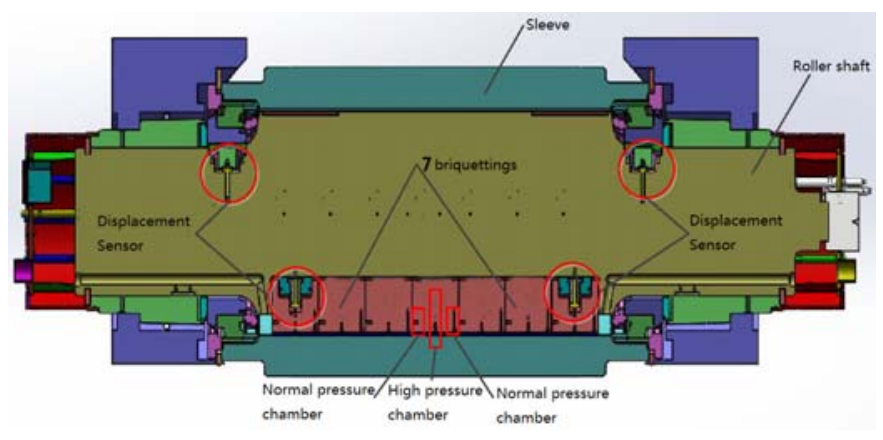

Fig.3. The DSR roll structure diagram

The seven briquetting Installed on the spindle don't rotate in the work, and realize the power transfer and a connection between the movingnonmoving parts through seven section dynamic and static pressure oil film with the rotating roller inner surface. Due to the seven briquetting pressure can be controlled by the according servo valve separately, so the rolling force can be dynamic distribution within the DSR. Through the passing of working roll, rolling force distribution along the strip transverse can achieve dynamic adjustment, so as to realize the purpose of controlling profile.

DSR technology calculate the optimal pressure distribution through the flatness gauge feedback value, and on the basis of internal pressure briquetting combination, through static pressure oil film to the roller set, thus forming various forms of strip shape control curve model, can control the whole and local, symmetric and asymmetric flatness defects; Press block is driven by the hydraulic pressure, has the same online adjusting speed and bending, dynamic response is much higher than that of roll shift class shape technology.

\section{THE STRUCTURE DESIGN OF TEST BED}

After several times of modification design shape, the final test bed material object is shown in figure 4, test bed is made of $2 \mathrm{~mm}$ thick high quality coldrolled steel plate after laser cutting, bending, grinding, welding, surface electrostatic plastic spraying, high temperature baking process. Its appearance looks like a piano, the overall height is $1200 \mathrm{~mm}$, under the premise of not affecting the function of test bed, this height for operators can easily put a few small parts temporarily at the top platform of the test bed. The upper set panel of the test bed has a caster angle, from the perspective of the visibility of the operator, this kind of design is very desirable. Middle extended part is the operation panel, its design height is $675 \mathrm{~mm}$, the operator can operate on the operation panel when he is standing with arms natural prolapse. Bottom part is designed to adduction first, then naturally turn out a radian to increase the contact area of the ground, this is from stability and the ergonomics point of view to consider. In this way, the center of gravity of test bed can be focused on the interior of the four corners, so as to make the test bed gravity stability.

From the aspects of ergonomics, operators can naturally put their feet down to the bottom of the operation panel, even sitting in a chair, space of the lower part of test bed is enough to meet the requirements, is very comfortable. In addition, the test bed's main edge horn is designed to rounded corners, it's safe and beautiful. The hole size of the parts for installation have been drawn on the facade version of the test bed. Test bed side lower part arrange signal interface for installing overloading aviation plug, it's convenient for operations of installation and maintenance.

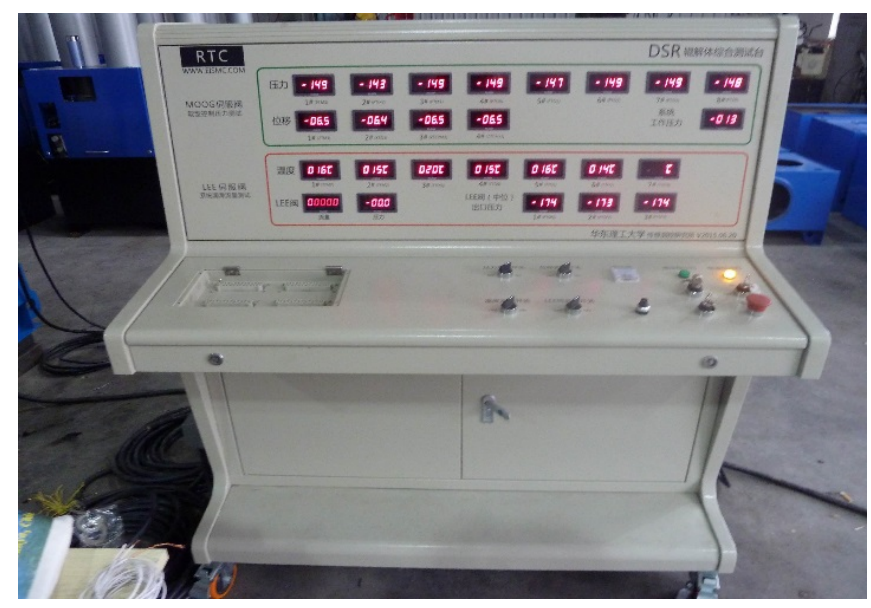

Fig.4. The final test bed material object

\section{THE FUNCTION ANALYSIS OF TEST BED}

DSR roll disintegrated comprehensive test bed integrates a variety of functions, involving cross-link of multidisciplinary domains such as machine, electricity, liquid. The function design of the DSR roll test bed mainly divided into three pieces, in the upper portion of the test bed is display table display area; At the bottom of the test bed on the right side is the function control area, the layout of control switch, signal lamp, etc.; At the bottom of the DSR roll test bed on the left is an external test port area. The DSR 
roll test bed control panel layout is shown in figure 5.

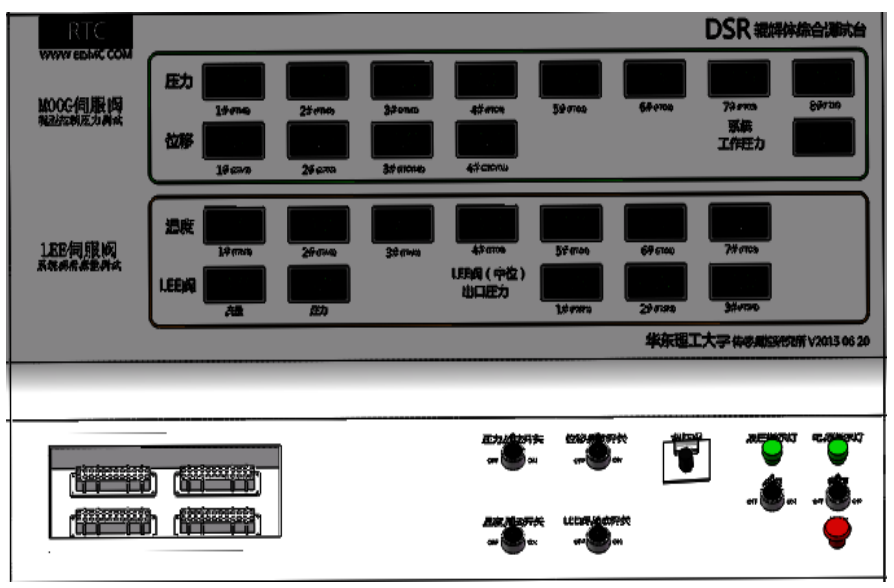

Fig.5. The test bed control panel layout

\subsection{Introduction to the data display area}

Due to the test bed monitoring object is more, there are 7 pressure signals, 7 temperature signals, 4 displacement and 21 flow signals. Therefore, according to the characteristics of the measured object we divide it into the MOOG servo valve roll shape control and LEE servo valve system lubrication two area. Roll shape control area include the pressure and displacement signals, system lubrication area include temperature and flow signals, two partitions arranged from top to bottom, distinguish and use different color line. Such, original number of test signal becomes clearer, that we can comfortably and accurately read various measurement data.

The main test object of the test bed are various sensors, the purpose is to make sure they work properly. Sensor signal display module circuit is shown in figure 6.

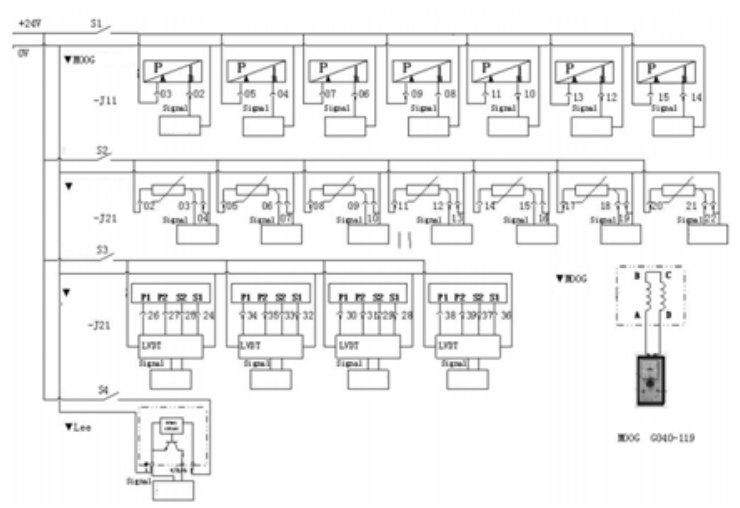

Fig.6. Sensor signal display module circuit

We adopt digital display instrument to show the data reading. The digital display instrument connection diagram in the DSR roll disintegrated comprehensive test bed is shown in figure 7 .

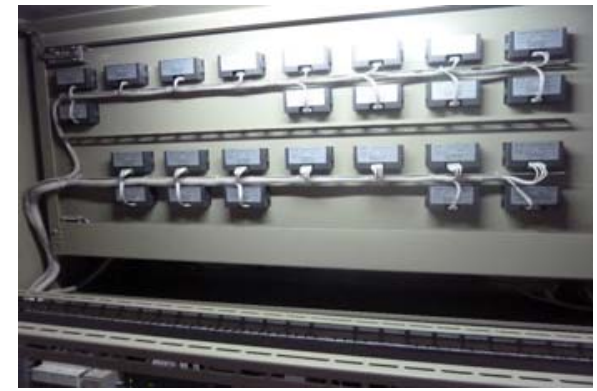

Fig.7. Digital display table connection diagram in the test bed

\subsection{Introduction to the function control area}

In the test bed operation area there are three main power control switch: the total power switch, the power switch of the hydraulic station and abrupt stop button. The power switch is equipped with the corresponding indicator light such as hydraulic indicator, power light.

The total power switch control the power supply of the whole test bed including sensors within the DSR roll, and the control power supply voltage is $220 \mathrm{v}$. The power switch of the hydraulic station is to control the hydraulic motor and pump power. Supplying for sensor and acquisition module is 150 $\mathrm{w}$ switching power supply, power supply voltage is $24 \mathrm{v}$. Abrupt stop button can quickly cut off the total power of test bed and hydraulic station, have the effect of security.

The test bed has four testing functions: Moog servo valve pressure test, temperature sensor test, displacement sensor test, Lee valve flow rate and pressure test.

Above four kinds of test functions, only the process of the temperature sensor test don't need hydraulic oil supply, the other three tests need continuous hydraulic oil supply. In addition, due to the hydraulic station can only provide a kind of oil pressure, Moog valve pressure test, displacement sensor test and Lee valve test can't conduct simultaneously. Test action logic table is shown in figure 8 .

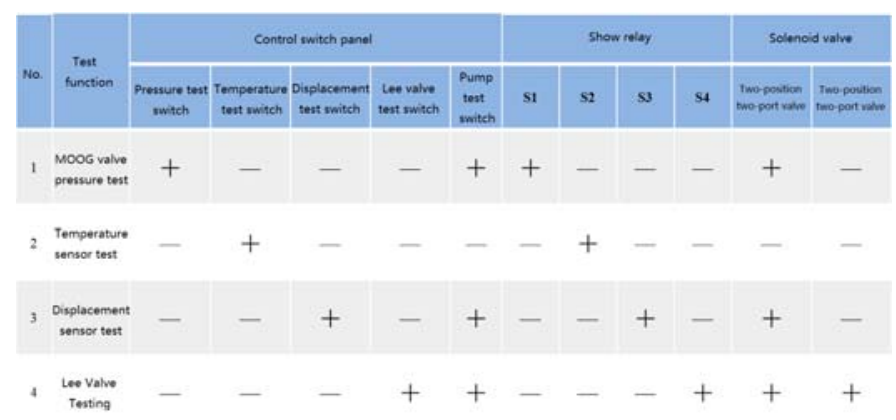

Fig.8. Test action logic table 


\subsection{Introduction to the external port area}

The area is used to directly measure electric parameters of each sensor such as resistance, and combine with digital display table to judge each sensor within the DSR roll is working correctly.

\section{CONCLUSION}

This device is applied to DSR roll disintegrated comprehensive test for the first time, and it can test 21 sensors within the DSR roll to ensure their normal work. This is a best example of a new idea from concept to reality, beneficial to improve the level of the maintenance of the DSR roll, form Baosteel's unique technology in DSR roll operation and maintenance. The research content have no reference at home and abroad, it's an original technology in the DSR roll maintenance area.

\section{REFERENCES}

Kajihara T. 1995. Rolling Characteristics of Cold Strips on Cross Rolling[J]. Journal of the JSTP, 12: 1403-1408.
Mizushima N. 1999. High-accuracy gauge control technologies over the full length and full width of cold rolled strip[J]. Kawasaki Steel Giho(Japan), 31(4): 240-245.

Tateno J J. 1999. Controlling edge drop by tapered-crown work roll shifting mill and work roll crossing mill in cold strip rolling[J]. Journal Japan society for technology of plasticity, 40: 653-657.

Wang J F. 2005. Operational results of the DSR installed on the No. 1 tandem cold mill of Baoshan Iron and Steel[J]. Revue de Métallurgie, 102(03): 241-249.

Yarita I. 1999. Recent activities in research of rolling technologies[J]. Kawasaki Steel Technical Report Eng 